\title{
Atlantoaxial joint distraction as a treatment for basilar invagination: A report of an experience with 11 cases
}

\author{
Atul Goel, Abhidha Shah \\ Department of Neurosurgery, King Edward $7^{\text {th }}$ Memorial Hospital and Seth GS Medical College, Parel, Mumbai, Maharashtra, India
}

\begin{abstract}
Objective: A novel method of treatment of basilar invagination that involves distraction of the atlantoaxial joint using specially designed spiked spacers is described. Bone graft that is additionally placed within the appropriately prepared atlantoaxial joint and posterior to the arch of atlas and lamina of C2 provides bony fusion. Materials and Methods: Between December 2002 and April 2007, 11 patients underwent the discussed method of fixation at the Department of Neurosurgery, King Edward Memorial Hospital in Mumbai, India. All 11 patients had "congenital" basilar invagination and the symptoms were progressive in nature. Results: The mean follow-up period was 21 months (range 8-40 months). Neurological improvement and successful distraction with atlantoaxial stabilization and ultimate bone fusion was achieved in all the patients and was documented with dynamic radiography. There were no neurological, vascular, or infective complications. Conclusions: We conclude that the described method of atlantoaxial joint distraction and fixation provides an alternative treatment strategy for cases with basilar invagination. "Joint distraction" as a stand-alone method could provide reduction of basilar invagination and firm stabilization in such cases.
\end{abstract}

Key words: Atlantoaxial dislocation, atlantoaxial joint, atlas, axis, basilar invagination

A variety of methods have been described to treat basilar invagination. We had classified basilar invagination into two groups. ${ }^{[1,2]}$ In Group A basilar invagination, there was a "fixed" atlantoaxial dislocation and the tip of the odontoid process "invaginated" into the foramen magnum $^{[3]}$ and was above the Chamberlain line, ${ }^{[4]}$ McRae line of foramen magnum ${ }^{[5]}$ and Wackenheim's clival line ${ }^{[6]}$ whereas in Group B cases, the entire complex of clivus, basiocciput and the craniovertebral junction was rostrally located and the tip of the odontoid process was above the Chamberlain's line but below the McRae's and the Wackenheim's lines. In this group, there was no atlantoaxial dislocation.

In 2004, we described an alternative method of treatment of Group A basilar invagination that involved distraction of the atlantoaxial joint using metal spacers and plate and screw fixation of the lateral masses of atlas and axis. ${ }^{[1]}$ Subsequently, we have used this technique for treatment of fixed atlantoaxial dislocation and for craniovertebral instability in cases with rheumatoid arthritis..$^{[1,7-12]}$ In this report, we wish to put on record an alternative treatment strategy for Group A basilar invagination that involves forceful introduction of specially designed spiked titanium spacers within the atlantoaxial joint as a stand-alone method of treatment. We had described use of similar spiked spacers for "joint-jamming" in the treatment of mobile and reducible atlantoaxial dislocation. ${ }^{[13]}$ The technique simulates to an extent inter-body fixation and distraction methods used extensively for subaxial spine instability and for spondylolisthesis. Multiple ligamentous structures and axial loading by distraction of the facets provides stability to the region.

\section{Materials and Methods}

Between December 2002 and April 2006, 11 cases with Group A basilar invagination were treated by the described technique and are presented on the basis of a prospective analysis. Follow-up ranged from 8-40 months (average 21 months). All patients were investigated with magnetic resonance imaging (MRI), computerized tomography (CT) scanning and dynamic plain radiology.

\section{Results}

The clinical features of the cases are presented in Table 1. Trauma of varying severity was the principal precipitating factor in five cases. The duration of main neurological symptoms ranged from 2 months to 3 years (average duration being 8 months). The visual analogue scoring (VAS) was done to assess the severity of pain and Nurrick's grading was utilized to assess the extent of myelopathy. ${ }^{[14]}$

Radiographic studies: Measurements of structures based on radiological studies are shown in Table 2 . 


\begin{tabular}{|c|c|c|c|c|c|c|c|c|c|c|c|c|c|}
\hline & & & & $\mathrm{Ta}$ & I: Prin & pres & ing $\mathrm{c}$ & al feat & & & & & \\
\hline Clinical $f$ & & & & & & & & & & mber & atients & & \\
\hline & & & & & & & & perativ & & & & Pos & rative \\
\hline Neck pain & & & & & & & & $7(63)$ & & & & & \\
\hline Torticollis & restric & neck n & ment & & & & & $5(45)$ & & & & & \\
\hline Weaknes & & & & & & & & & & & & & \\
\hline Able to & unaid & & & & & & & $4(36)$ & & & & & \\
\hline Needec & port tc & & & & & & & $5(45)$ & & & & & \\
\hline Unable & alk ev & vith sup & & & & & & 2 (18) & & & & & \\
\hline Sensation & & & & & & & & & & & & & \\
\hline Normal & sation & & & & & & & $5(45)$ & & & & & \\
\hline Kinesth & sensa & $s$ affect & & & & & & $8(73)$ & & & & & \\
\hline Spinoth & ic ser & ions af & & & & & & $6(55)$ & & & & & \\
\hline Lower cra & nerves & ection & & & & & & $1(9)$ & & & & & \\
\hline Respirato & nbarra & nent & & & & & & $1(9)$ & & & & & \\
\hline & & Table & Pre & ive & logic & asur & nts & heir ch & es fo & ving s & & & \\
\hline Age/sex & & $\mathrm{L}(\mathrm{mm}$ & & & $\mathrm{L}(\mathrm{mm}$ & & & $\mathrm{L}(\mathrm{mm}$ & & Ome & ingle ( & ees) & Chiari \\
\hline & Pre & Post & $\overline{D t}$ & Pre & Post & $\overline{D t}$ & Pre & Post & $\overline{D t}$ & Pre & Post & Alt & \\
\hline $27 / \mathrm{M}$ & 8 & 0 & 8 & 5 & -2 & 7 & 13 & 0 & 13 & 76 & 85 & 9 & - \\
\hline $11 / M$ & 7 & 4 & 3 & 5 & 0 & 5 & 7 & 1 & 6 & 70 & 78 & 8 & - \\
\hline $15 / F$ & 5 & 0 & 5 & 2 & -2 & 4 & 4 & 1 & 3 & 55 & 80 & 25 & - \\
\hline $17 / \mathrm{M}$ & 10 & 0 & 10 & 8 & 1 & 7 & 11 & 2 & 9 & 75 & 86 & 11 & - \\
\hline $17 / M$ & 20 & 8 & 12 & 16 & 4 & 14 & 20 & 8 & 10 & 70 & 80 & 10 & - \\
\hline $19 / F$ & 20 & 6 & 14 & 6 & 0 & 6 & 4 & 0 & 4 & 70 & 80 & 10 & - \\
\hline $13 / F$ & 16 & 4 & 12 & 15 & 2 & 13 & 15 & 4 & 11 & 60 & 80 & 20 & - \\
\hline $7 / F$ & 17 & 8 & 9 & 12 & 3 & 9 & 10 & 3 & 7 & 40 & 75 & 35 & + \\
\hline $39 / F$ & 18 & 10 & 8 & 17 & 6 & 11 & 19 & 6 & 13 & 60 & 80 & 20 & + \\
\hline 19/M & 5 & 0 & 5 & 6 & -1 & 7 & 5 & -1 & 6 & 46 & 80 & 34 & - \\
\hline $29 / M$ & 8 & 2 & 6 & 7 & 2 & 5 & 6 & 0 & 6 & 40 & 80 & 40 & - \\
\hline
\end{tabular}

CL - Chamberlain's line; WL - Wackenhiem's line; ML - McRae's line; Pre - Preoperative; Post - Postoperative; Dt - Distraction; Alt - Alteration

Measurements were made on all available studies and were averaged. The landmarks used for measurements of various indices were used in our earlier study. ${ }^{[2]}$ There was no clear radiographic presence of mobile subluxation with flexion resulting in an increase in the atlantodental or clivodental interval, increased compromise of the canal diameter, or reduction in the girth of the brainstem. As per the defined parameters, there was an element of "fixed" atlantoaxial dislocation in all patients. Chiari I malformation was present in two cases. Syringomyelia was identified in one case. Element of mild to marked rotation in the atlantoaxial joint was seen in four cases. Partial or complete occipitalization of the atlas was present in all cases and fusion of $\mathrm{C} 2$ and C3 was observed in two cases. Os-odontoideum was seen in three cases.

Surgical technique of intraoperative joint distraction and reduction of fixed atlantoaxial dislocation: All patients underwent joint manipulation surgery [Figures 1-3]. One patient had undergone transoral decompression elsewhere. No patient underwent transoral decompression as a first-stage operation in our Institute. One patient with Chiari I malformation was operated upon previously by foramen magnum decompression as per our earlier policy of treatment. ${ }^{[2]}$ The basic surgical steps of the joint distraction surgery are the same as discussed in our papers on the subject. ${ }^{[1,7-12,16,17]}$ Cervical traction is given prior to induction of anesthesia and the weights were progressively increased to approximately one-fifth of the total body weight. The patient is placed prone with the head end of the table elevated to about 35 degrees. The atlantoaxial facet joints are widely exposed on both sides after sectioning of the large $\mathrm{C} 2$ ganglion. The exposure of the facet of the atlas was significantly difficult as in all patients there was an assimilation of the atlas resulting in rostrally located C1-C2 joint complex. The joint capsule is excised and the articular cartilage of facet of atlas and axis is widely removed using microdrill. The facets are distracted with the help of varying sizes of osteotomes, which are introduced in the joint with their sharp edge and then turned 90 degrees to effect distraction. A specially designed spiked titanium spacer suitable for the region is impacted into the joint space using suitable instruments. The average size of the spacers used in the present cases measured $12 \mathrm{~mm}$ in length, $10 \mathrm{~mm}$ in breadth and $8 \mathrm{~mm}$ in height [Figure 4]. The status of the dislocation and of basilar invagination is evaluated by intraoperative radiographic control. Pieces of corticocancellous bone graft harvested from the iliac crest are additionally stuffed into the joints in the space available by the sides of the spacer [Figures 1-3]. The sizes of the spacers used depended on the space available within the distracted joint space. Additional bone graft was placed between the posterior elements of C1-suboccipital bone complex and C2 after decorticating the host bone area with a suitable drilling 

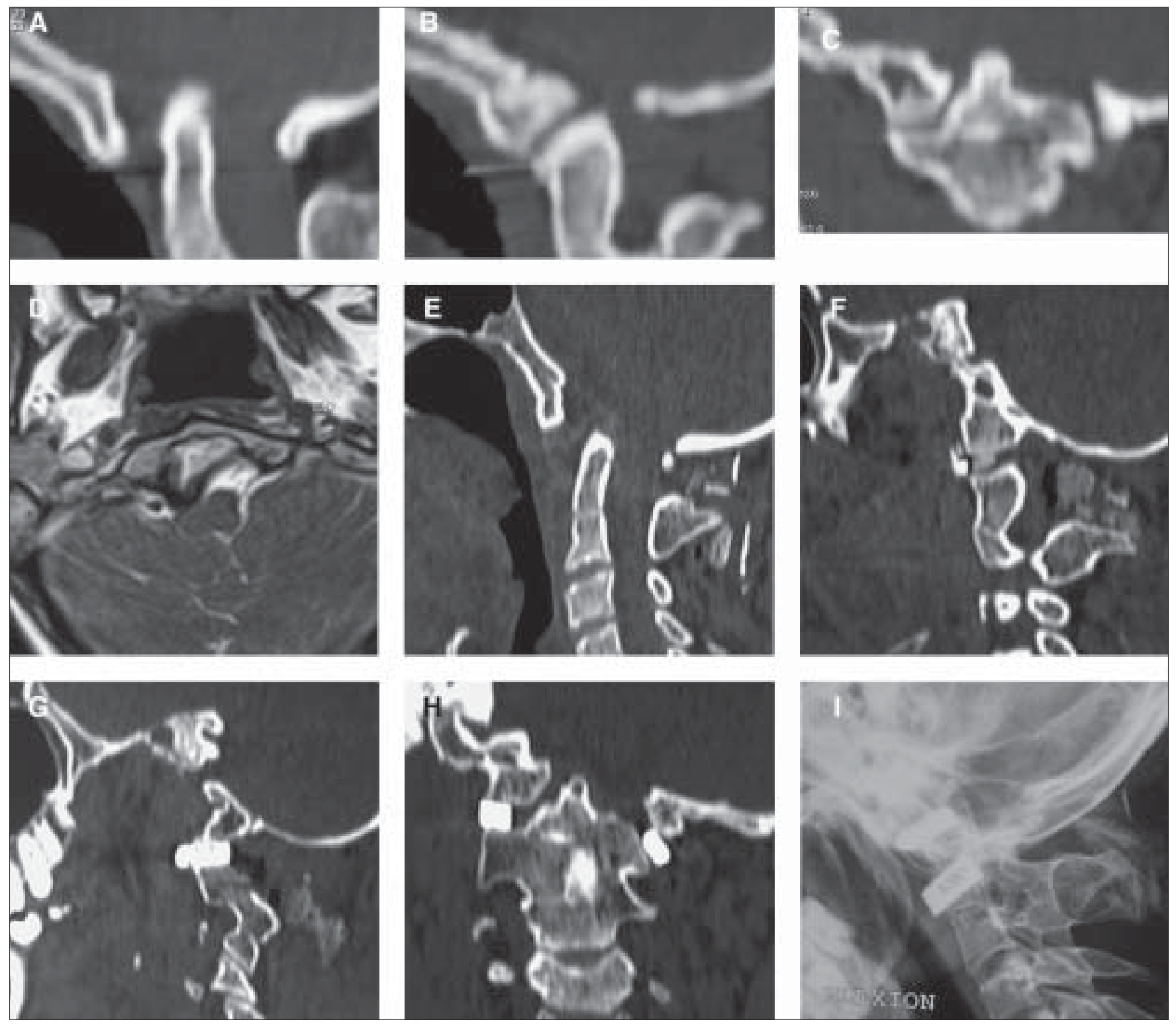

Figure 1: Images of a 17-year-old male patient. (A) Preoperative CT scan shows basilar invagination. Assimilation of the atlas can be observed.

(B) Preoperative CT scan showing the abnormal alignment of the atlantoaxial. (C) Coronal images of the CT scan showing the craniovertebral junction and the joints. (D) Axial section of the MRI showing marked rotation of the odontoid process. (E) Postoperative CT scan showing the reduction of basilar invagination and improvement in the craniovertebral alignments. (F) Postoperative sagittal cut through the atlantoaxial joint showing marked realignment of the facets and the joint. (G) Postoperative sagittal cut showing the spacer in the atlantoaxial joint and the realignment. (H) Postoperative coronal section showing the spacers in both the atlantoaxial joints. (I) Postoperative X-ray (lateral view) showing spacers in both the atlantoaxial joints. Evidence of bone fusion is noted

burr. Postoperatively, the traction is discontinued and the patient is placed in a four-post hard cervical collar for 3 months and all his physical activities involving the neck are restrained during the period. However, sitting and standing posture was encouraged as during these maneuvers probably the weight of the head assisted in further impaction of the spacers and stability of the joint.

Results of surgery: The follow-up ranged from 8 to 40 months (average being 21 months). All patients improved in the symptoms to varying degrees following surgery [Tables 1 and 2]. There were no intraoperative or postoperative vascular, neurological or infective complications. The changes in various radiological parameters when compared to the preoperative parameters are elaborated in Table 2. None of the patients suffered a delayed neurological worsening meriting the need for a transoral or a posterior foramen magnum decompression or any other kind of surgical procedure. No patient needed a re-exploration for failure of the fixation or migration of the implant. Immediate postoperative and follow-up radiographs confirmed fixation and fusion and reduction of the basilar invagination. Bone fusion was assumed to have occurred when the implant could maintain the distraction and reduction of the basilar invagination on dynamic radiographs 6 months after surgery. Successful 

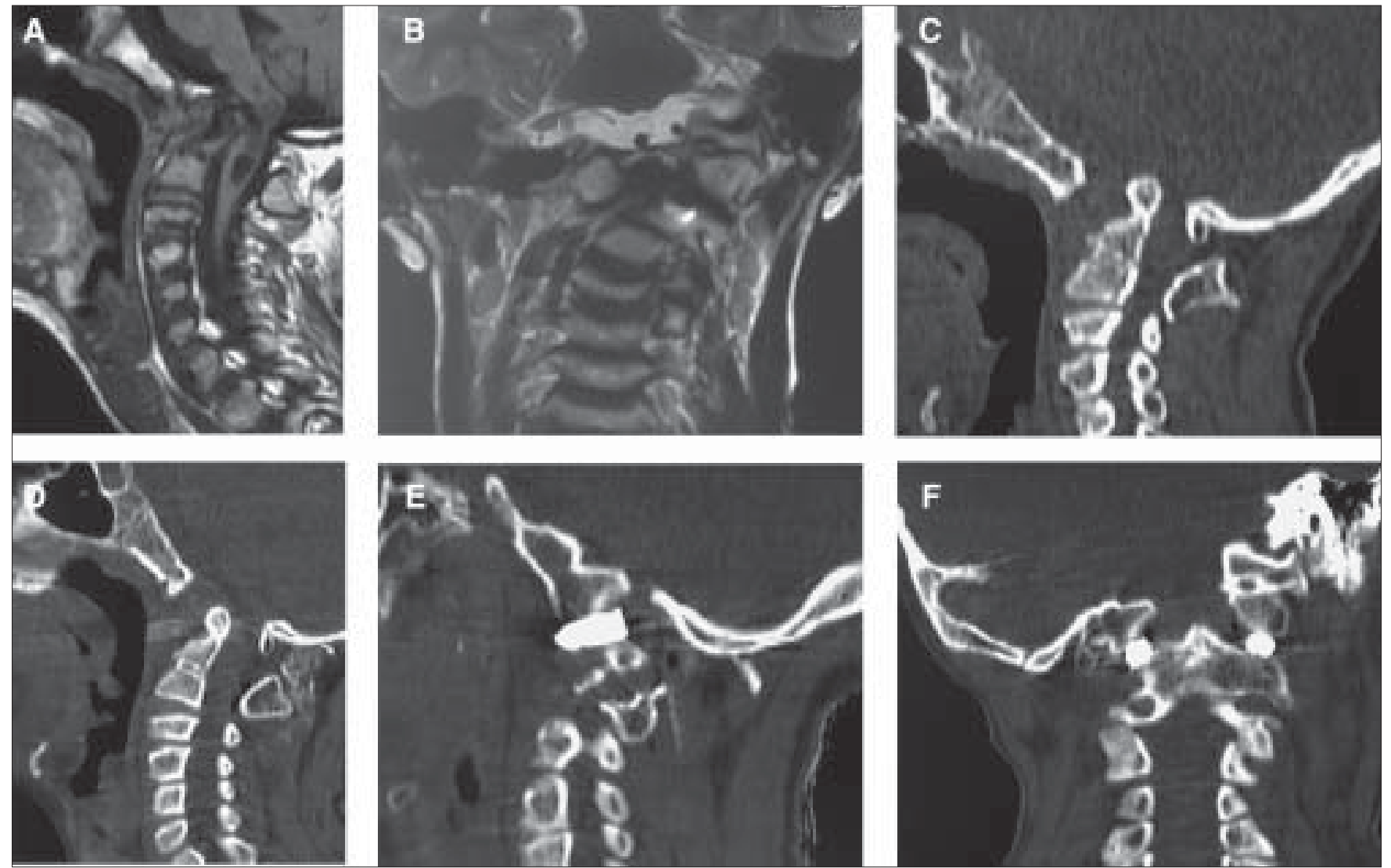

Figure 2: Images of an 11-year-old male patient. (A) Preoperative MRI showing basilar invagination (transoral surgery was already attempted) and cord changes. (B) Coronal MRI showing marked rotation of the craniovertebral junction. (C) Sagittal section of CT scan showing basilar invagination and fixed atlantoaxial dislocation. (D) Postoperative sagittal image showing reduction of basilar invagination. (E) Sagittal image showing spacer in the atlantoaxial joint. (F) Coronal section showing spacers in both the atlantoaxial joints and the distraction

and sustained distraction and reduction of basilar invagination was observed in all patients. Torticollis improved significantly following surgery in all the four patients with preoperative symptom of torticollis. There was at least some degree of sensory loss in the distribution of the $\mathrm{C} 2$ nerves in all cases.

\section{Discussion}

Despite the fact that a number of techniques are now available for the treatment of basilar invagination, search for a most appropriate option still continues. Currently, the most accepted and used form of treatment of cases with Group A basilar invagination is transoral decompression of the bony compressive elements and posterior craniocervical or atlantoaxial fixation..$^{[2,18,19]}$ We had described an alternative method of treatment that involved distraction of the facets of the atlantoaxial joint and impaction of metal spacers and bone graft within it. ${ }^{[1,7-12]}$ Additionally, we fixed the joint, using direct implantation of the screws in the lateral masses of atlas and axis. The possibility of treatment of basilar invagination by cranial traction ${ }^{[20]}$ and by distraction has also been suggested by other authors.

Basilar invagination has been considered by several authors to be a "fixed" anomaly. Dynamic imaging in this condition seldom shows evidence of abnormal movements of the atlantoaxial joint or increased compromise of the spinal canal dimension on flexion of the neck. Fixation of the region is recommended by several authors after transoral decompression, as bone resection and ligamentous laxity after surgery is said to de-stabilize the region. Some authors have recommended limited transoral bone resection to avoid instability of the region. In our earlier report on the subject, we had hypothesized that the abnormal angulation of the facets of atlas and axis may be the cause of progressive slip of the axis into atlas, a process that results in superior migration of the odontoid process. The instability of the atlantoaxial joint thus appears to be the primary cause of basilar invagination. The history of trauma preceding the clinical events, predominant complaint of pain in the neck and the improvement in neurological symptoms following institution of cervical traction suggests "vertical" instability of the craniovertebral region. The process of basilar invagination was likened by us to lumbosacral spondylolisthesis. ${ }^{[21]}$ Several authors have successfully treated lumbosacral spondylolisthesis by interbody cages/spacers that result in distraction, reduction and fixation of the listhesis. The combined 

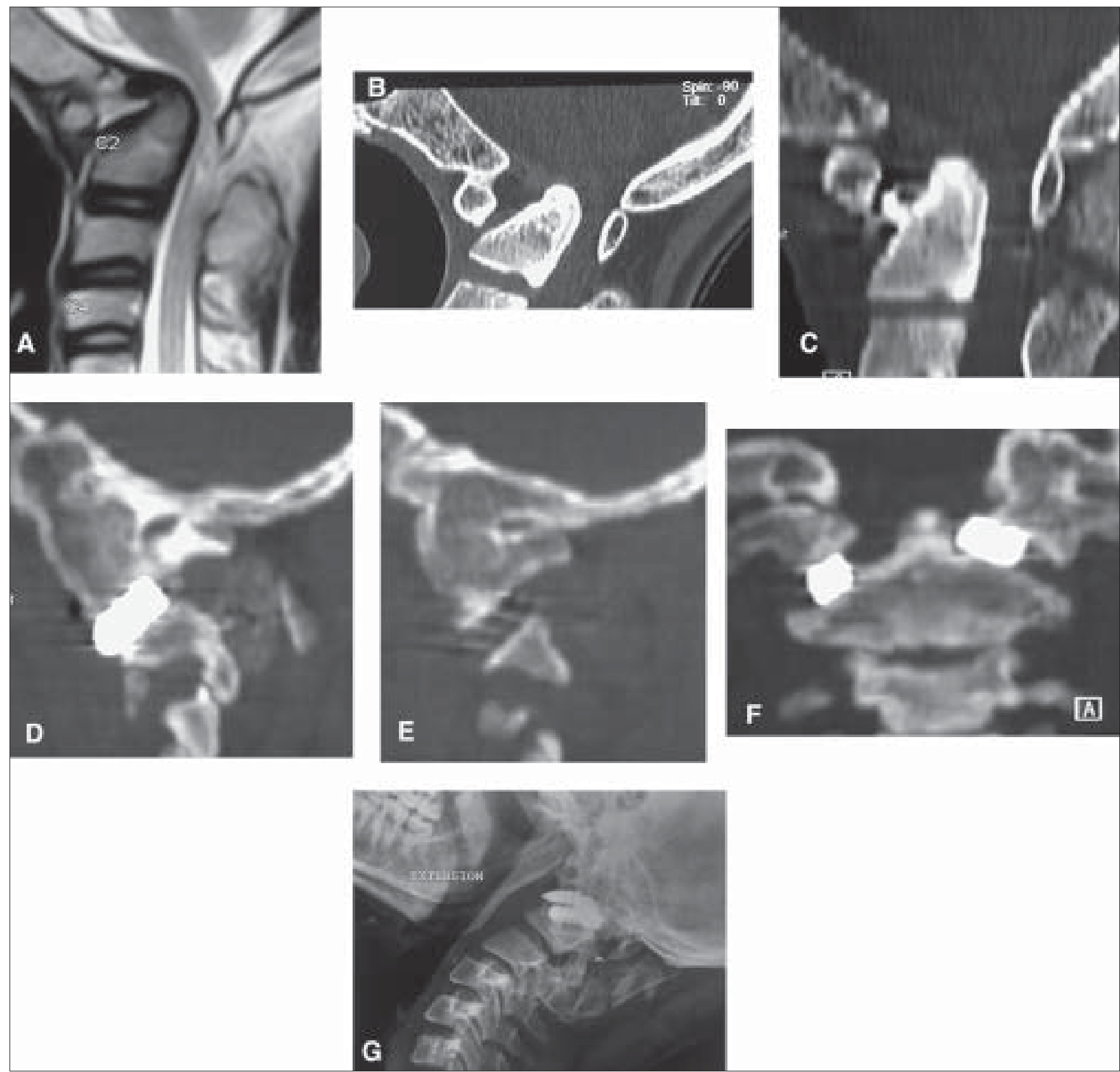

Figure 3: Images of a 15-year old female. (A) Preoperative MRI showing basilar invagination and fixed atlantoaxial dislocation. (B) Preoperative CT scan showing relatively minor basilar invagination and fixed atlantoaxial dislocation. (C) Postoperative CT scan showing incomplete but significant reduction of basilar invagination and atlantoaxial dislocation. (D) Sagittal image through the atlantoaxial joint showing the spacer. (E) Sagittal image through the joint showing the distraction and opening up of the joint. (F) Coronal image of CT scan showing the spacers in both the atlantoaxial joints. (G) Postoperative X-ray showing the spaces in the joints

size of the facets of atlas and axis is more than the size of the cervical vertebral bodies. ${ }^{[22]}$ The facets of atlas and axis are significantly stronger and heavier than the cervical vertebral bodies and are made up predominantly of cortical rather than cancellous bone. Wide removal of atlantoaxial joint capsule and articular cartilage by drilling and subsequent distraction of the joint by manual manipulation provided a unique opportunity to obtain reduction of the basilar invagination and of atlantoaxial dislocation. The distraction of the facets by specially designed spacers on both sides appeared to provide axial loading of number of ligaments in the region and stabilization, and provides an appropriate milleu for bone fusion that will ultimately result in fusion of the region. The range of movements in the atlantoaxial joint is not excessive as in congenital mobile atlantoaxial dislocation and therefore the spacer is more stable within the joint and possibility of its migration becomes less.

A variety of distraction cages and spacers are 


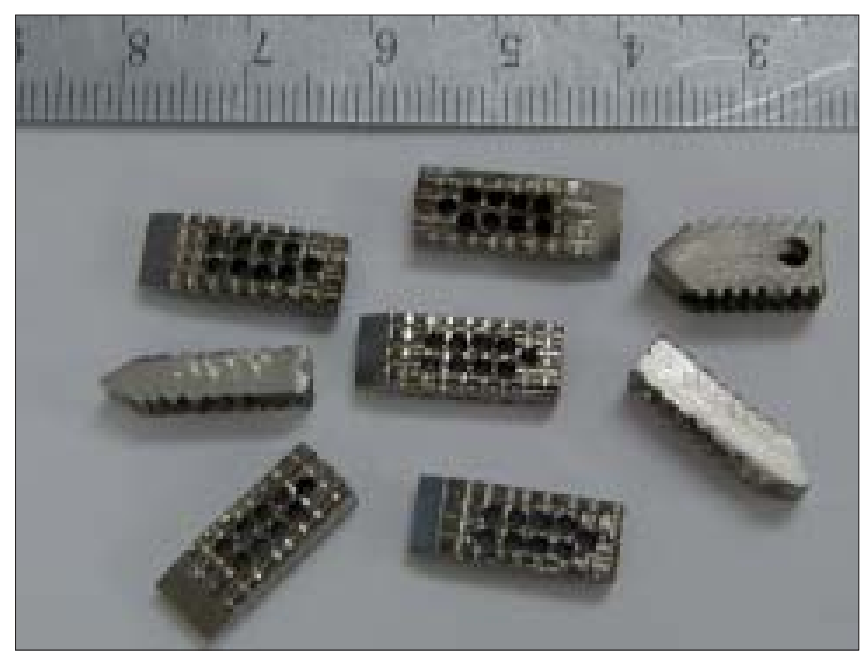

Figure 4: Picture showing the spacers of various sizes. The spacers are made of titanium and have spikes. There are multiple holes within the body of the spacers for assistance with bone healing. The spacers are tapered at leading edge to assist insertion within the joint. The base of the spacer has a transverse slot for stability of a suitable osteotome during hammer insertion

currently commercially available for interbody subaxial stabilization. There have been several innovations in the design, which makes them more biomechanically effective and surgeon-friendly for easier and safer introduction. The specially designed titanium spacer used in our presented technique was available to us in multiple sizes. It is tapered in its leading edge to assist insertion within the joint. The base of the spacer has a transverse slot for stability of a suitable osteotome during hammer insertion. Multiple small holes within the body of the spacers provide avenue for bone fusion across the implant.

Large veins and venous sinuses in the region of the $\mathrm{C} 2$ ganglion and lateral masses frequently cause troublesome bleeding. ${ }^{[13,16,17]}$ The venous bleeding is controlled with judicious use of diathermy and packing of the extradural space and space lateral to the facets with Surgicel and/or Gelfoam. The head-high position used for surgery provides counter-traction and helps to reduce venous engorgement in the operative field. Exposure of the joint is significantly more difficult in cases with basilar invagination than in cases with plain atlantoaxial dislocation. Although superior displacement of the ganglion can occasionally provide space for introduction of the spacer and bone graft, sectioning of the large $\mathrm{C} 2$ ganglion avoids undue traction on the nerve and provides a panoramic view of the region and manipulations of the facets can be done under direct vision. It also appears that sectioning of the ganglion and subsequent packing of the region lateral to the joint can assist in controlling the venous bleeding.

The procedure provided sufficient stability to the region, and any other fixation method could be avoided. However, if the surgeon finds the stability inadequate, all other described techniques of fixation, midline and lateral, can be simultaneously employed. Although, we still consider simultaneous fixation of the region with plates and screws in the lateral masses as the more optimum form of treatment, in selected cases the stability provided by the spacers was so firm that all other forms of fixation could be avoided. In some cases with basilar invagination, exposure of the facet of the atlas for screw insertion may even be technically difficult, particularly in cases with assimilation of atlas. As insertion of screw in the facets of atlas and axis is not involved, the technique becomes simpler and the problem of vertebral artery injury is avoided. Exact anatomical understanding of the region is mandatory and can be based on cadaveric study. ${ }^{[22]}$ However, our experience in exposure of the atlantoaxial joint over several years ${ }^{[14]}$ and distraction of atlantoaxial joint in the treatment of basilar invagination and cases with "fixed" atlantoaxial dislocation probably helped us in making the presented technique relatively straightforward.

The fixation was seen to be strong enough to sustain the vertical, transverse and rotatory strains of the most mobile region of the spine. All patients had a sustained neurological improvement of varying degrees suggesting the effectiveness of the operation. Resection of the $\mathrm{C} 2$ ganglion is necessary to achieve the exposure. In our present experience and that reported by us earlier, we observed that the resection of the $\mathrm{C} 2$ ganglion results in an area of numbness along the distribution of the nerve. However, the area of numbness progressively reduces in size over the years and was not seen to be a disabling feature in any case. All the activities related to neck movements were restricted for a 3-month period to provide an opportunity for bone fusion in the joint. However, sitting and standing posture was encouraged as during these maneuvers probably the weight of the head assisted in further impaction of the spacers and stability of the joint.

As no wire, screws, plates and rods were used for fixation, as is conventionally the norm; the extent of stability provided by the implant will have to be assessed by a larger experience over a longer period of time. The issues of use of most appropriate size and type of spacer and extent of optimum distraction necessary will have to be rationalized so as to achieve satisfactory stability of the region and avoid implant migration.

\section{Conclusion}

The alternative technique of joint distraction probably has a potential for treatment for select cases with basilar invagination. The author is convinced that future improvement and innovations in design and material of spacer and instrumentation for its introduction 
in the atlantoaxial joint will make this technique biomechanically more stable and surgeon friendly in its use.

\section{References}

1. Goel A. Treatment of basilar invagination by atlantoaxial joint distraction and direct lateral mass fixation. J Neurosurg Spine 2004;1:281-6.

2. Goel A, Bhatjiwale M, Desai K: Basilar invagination: A study based on 190 surgically treated cases. J Neurosurg 1998;88:962-8.

3. Von Torklus D, Gehle W. The upper cervical spine: Regional anatomy, pathology, and traumatology. A systematic radiological atlas and textbook. New York: Gruneand Stratton; 1972. p. 1-98.

4. Chamberlain WE. Basilar impression (platybasia): A bizarre developmental anomaly of the occipital bone and upper cervical spine with striking and misleading neurologic manifestations. Yale J Biol Med 1939;11:487-96.

5. McRae DL. Bony abnormalities in the region of foramen magnum: correlation of anatomic and neurologic findings. Acta Radiol 1953;40: 335-54.

6. Thiebaut F, Wackenheim A, Vrousos C. New median sagittal pneumostratigraphical findings concering the posterior fossa. J Radiol Electrol 1961;42:1-7.

7. Goel A. Progressive basilar invagination after transoral odontoidectomy: Treatment by atlantoaxial facet distraction and craniovertebral realignment. Spine 2005;30:E551-5.

8. Goel A. Craniovertebral anomalies: Role for craniovertebral realignment. Neurol India 2004;52:427-9

9. Goel A, Kulkarni AG, Sharma P. Reduction of fixed atlantoaxial dislocation in 24 cases: Technical note. J Neurosurg Spine 2005;2:505-9.

10. Goel A, Pareikh S, Sharma P. Atlantoaxial joint distraction for treatment of basilar invagination secondary to rheumatoid arthritis. Neurol India
2005;53:238-40.

11. Goel A, Sharma P. Craniovertebral junction realignment for the treatment of basilar invagination with syringomyelia: Preliminary report of 12 cases. Neurol Med Chir (Tokyo) 2005;45:512-8.

12. Goel A, Sharma P. Craniovertebral realignment for basilar invagination and atlantoaxial dislocation secondary to rheumatoid arthritis. Neurol India 2004;52:338-41.

13. Goel A. Atlantoaxial joint 'jamming' as a treatment for atlantoaxial dislocation: A preliminary report. J Neurosurg (Spine) 2008.

14. VanGilder JC, Menezes AH, Dolan KA. The Craniovertebral Junction and Its Abnormalities. Mount Kisco, NY: Futura; 1987. p. 29-68.

15. Goel A, Desai K, Muzumdar D. Atlantoaxial fixation using plate and screw method: A report of 160 treated patients. Neurosurgery 2002;51:1351-7.

16. Goel A, Laheri VK. Plate and screw fixation for atlanto-axial dislocation: Technical report. Acta Neurochir (Wien) 1994;129:47-53.

17. Bonney G, Williams JP. Transoral approach to the upper cervical spine. J Bone Joint Surg Br 1985;67:691-8.

18. Crockard HA. Anterior approaches to lesions of the upper cervical spine. Clin Neurosurg 1988;34:389-416.

19. Menezes AH. Primary craniovertebral anomalies and hindbrain herniation syndrome (Chiari I): Data base analysis. Pediatr Neurosurg $1995 ; 23: 260-9$.

20. Kothari M, Goel A. Transatlantic odonto-occipital listhesis: The so-called basilar invagination. Neurol India 2007;55:6-7.

21. Cacciola F, Phalke U, Goel A. Vertebral artery in relationship to C1-C2 vertebrae: An anatomical study. Neurol India 2004;52:178-84.

22. Gupta S, Goel A. Quantitative anatomy of lateral masses of the atlas and axis vertebrae. Neurol India 2000;48:120-5.

Accepted on 19-03-08

Source of Support: Nil, Conflict of Interest: None declared.

\section{Author Help: Online Submission of the Manuscripts}

Articles can be submitted online from http://www.journalonweb.com. For online submission articles should be prepared in two files (first page file and article file). Images should be submitted separately.

\section{1) First Page File:}

Prepare the title page, covering letter, acknowledgement, etc., using a word processor program. All information which can reveal your identity should be here. Use text/rtf/doc/pdf files. Do not zip the files.

\section{2) Article file:}

The main text of the article, beginning from Abstract till References (including tables) should be in this file. Do not include any information (such as acknowledgement, your names in page headers, etc.) in this file. Use text/rtf/doc/pdf files. Do not zip the files. Limit the file size to $400 \mathrm{~kb}$. Do not incorporate images in the file. If file size is large, graphs can be submitted as images separately without incorporating them in the article file to reduce the size of the file.

3) Images:

Submit good quality color images. Each image should be less than 1024 kb (1 M B ) in size. Size of the image can be reduced by decreasing the actual height and width of the images (keep up to about 6 inches and up to about 1200 pixels) or by reducing the quality of image. J PEG is the most suitable file format. The image quality should be good enough to judge the scientific value of the image. Always retain a good quality, high resolution image for print purpose. This high resolution image should be sent to the editorial office at the time of sending a revised article.

4) Legends:

Legends for the figures/images should be included at the end of the article file. 